\title{
口腔癌相关唾液肿瘤生物标志物的分析检测研究进展
}

\author{
金金王王晓英* \\ (东南大学公共卫生学院 环境医学工程教育部重点实验室＼cjkstart南京 210009)
}

\begin{abstract}
摘要口腔癌系头颈部癌, 癌组织均位于口腔内, 其非侵入性早期诊断是减少该病死亡的有效手段. 唾液系口腔癌变 相关物质首先释放进入的体液, 取材方便, 安全无创, 是口腔癌普查笁选、早期诊断的首选指标. 本文对唾液肿瘤生物 标志物的种类、目前国内外常用的检测方法进行概述, 重点阐述新型电化学生物传感方法在口腔癌相关唾液肿瘤生物 标志物检测方面的相关应用及其最新研究进展. 并对口腔癌相关唾液肿瘤生物标志物电化学传感技术的未来发展方向 提出展望, 拟为其深入研究与应用提供参考.
\end{abstract}

关键词口腔癌; 唾液; 肿瘤生物标志物; 检测方法; 电化学生物传感器

\section{Progress in Analysis and Detection of Salivary Tumor Biomarkers Associated with Oral Cancer}

\author{
Jin, Xin Wang, XiaoYing* \\ (Key Laboratory of Environmental Medicine Engineering, Ministry of Education, School of Public Health, \\ Southeast University, Nanjing 210009, China)
}

\begin{abstract}
Oral cancer is head and neck cancer, and cancer tissue is located in the oral cavity. The non-invasive early diagnosis is an effective method to reduce the death of the disease. The oral cancer-related substances are first released into the saliva, which is convenient, safe and non-invasive, and is the first choice for screening and early diagnosis of oral cancer. In this paper, the specific types and the commonly used detection methods of the salivary tumor biomarkers at home and abroad were summarized and compared. Specifically, the latest application of new electrochemical biosensor in the detection of the salivary tumor biomarkers associated with oral cancer was mainly described. Futhermore, the summary of its future directions and the potential applications was proposed, which provided reference for the further research and application of the salivary tumor biomarkers in oral cancer.
\end{abstract}

Keywords oral cancer; saliva; tumor biomarker; detection technology; electrochemical biosensor

\section{1 引言}

口腔癌(oral cancer)系发生在口腔领面部的恶性肿 瘤总称. 临床实践中按其部位可分为牙龈、舌、腭、口 底、口咽、涎腺、唇癌及发生于颜面部皮肤黏膜的癌症 这八类，约 $90 \%$ 的口腔癌属于上皮源性的鳞状细胞癌 (oral squamous cell carcinoma, OSCC) ${ }^{[1]}$. 对于 OSCC 的 临床诊断, 常规的方法有临床观察、染色检查、组织学 和细胞学检查 ${ }^{[2]}$. 虽然临床观察简便实用, 医生可通过 简单的视、扪诊来检查口腔黏膜有无病变, 但仅靠肉眼 观察较难作出准确判断. 染色检查是一种无创、能方便 检测口腔癌前病变高危性的辅助方法, 但染色结果的准 确性依赖于良好的染色技术和高分辨率显微镜, 这对医 生的要求较高, 也增加了检测成本. 组织学检查虽可作 为 OSCC 癌前病变和确诊的依据, 但须取得组织标本进 行活检. 活检系有创检查, 依从性较差, 术后的痒痕亦 会影响观察. 此外, 细胞学检查是不愿意接受活检病人
的一种较好的选择. 但上皮深层细胞不易取到, 检测的 准确性较低. 常规的诊断方法均针对肿瘤生长到一定程 度, 具有临床症状时才有实际意义. 但 OSCC 的潜伏期 较长，其早期症状与口腔炎、口腔溃疡相似，不易被发 现; 临床确诊后约三分之二的患者已进入中晚期, 生存 率较差 ${ }^{[3]}$. 随着免疫学、分子生物学的快速发展, 人们对 OSCC 的发病机制有了更深入的认识，已经发现多种与 OSCC 细胞产生、增殖、调亡等一系列过程相关的重要 的生物标志物(tumor biomarker, TM) ${ }^{[4]}$. 其可存在于肿 瘤细胞和组织中, 也可进入体液中, 反映 OSCC 发生发 展过程中的分子及遗传学改变, 是衡量疾病存在状况和 严重程度的可测指标, 其为 OSCC 的早诊早治提供了新 手段.

随着 TM 检测手段的不断进步, TM 检测的中介物 范围亦不断扩大, 除了常规的血清, 其它的体液也逐渐 被用于临床辅助诊断, 如唾液、尿液、支气管灌洗液、

\footnotetext{
*E-mail: wxy@seu.edu.cn

Received October 7, 2018; published December 3, 2018.

Project supported by the National Natural Science Foundation of China (Nos. 81600179, 81302472) and "Blue Project" funded by universities in Jiangsu. 项目受国家自然科学基金(Nos. 81600179, 81302472)和江苏高校 “青蓝工程” 资助.
} 
胸腔积液、腹水、乳头溢液、精液等. 由于唾液中含有 口腔组织细胞及其代谢或分泌产物，当口腔黏膜组织发 生癌变时, 肿瘤细胞合成和分泌的物质首先释放到病变 的局部体液中, 后才经血液或淋巴液回流进入血循环. 因此, 检测唾液中口腔癌相关 TM 含量比检测血清更加 敏感. 唾液又因取材方便、安全无创伤且可方便地用于 大规模的普查篮选, 已然成为早发现、早诊断口腔癌的 首选指标.

\section{2 唾液肿瘤生物标志物的分类}

唾液是口腔内存在的一种无色且稀薄的液体，由腮 腺、领下腺、舌下腺及许多小黏液腺分泌. 健康的成年 受试者每天可产生 500 1500 mL 的唾液, 一些生理和 病理条件可改变唾液的产生和组成 ${ }^{[5]}$. 例如味觉刺激、 病毒感染、炎症和患有口腔癌. 酸性食物刺激会增加唾 液的流速和流量 ${ }^{[6]}$. 病毒感染常引发口腔内部炎症, 这 些炎症将会进一步恶化成口腔癌, 其伴随着唾液中生物 标志物的种类、状态的改变. 如在受人类巨细胞病毒感 染后引发的慢性牙周炎过程中 ${ }^{[7]}$, 炎症细胞因子白细胞 介素-1(IL-1), IL-6 和肿瘤坏死因子- $\alpha(\mathrm{TNF}-\alpha)$ 的浓度升 高, 且这些细胞因子在口腔局部产生高度组织化的炎症 反应 ${ }^{[8]}$. 炎症反应进一步恶化过程中, 口腔中的微生物 及其产物会激活成纤维细胞和免疫细胞, 产生活性氧, 从而在上皮细胞中引发 DNA 损伤 ${ }^{[9]}$. 研究表明从口腔 内的病毒感染到口腔癌的发生是一个动态变化过程, 期 间唾液中生物标志物会发生系列改变.

口腔内环境的变化引起标志物改变的机制尚未明 确, 但口腔唾液内含多种生物分子, 其与口腔癌的发生 发展及治疗预后有着密切的诱因关系 ${ }^{[10]}$. 常见的口腔 癌相关唾液生物标志物主要有基因组、转录组、蛋白质
组和微生物组 ${ }^{[11]}$ (见表 1$)$.

基因组：基因组的不稳定性如启动子甲基化、杂合 性丢失、肿瘤相关基因的突变、基因扩增等是癌症发生 发展的主要原因. 其中, 基因的异常甲基化(如启动子 超甲基化)在 OSCC 中较常见. 如 Rosas 等 ${ }^{[12]}$ 证实 $\mathrm{CdkN} 2 \mathrm{~A} / \mathrm{p} 16 、 \mathrm{MGMT}$ 或 DAP-K 基因中至少一种可在 OSCC 中发生异常甲基化. 杂合性丢失(loss of heterozygosity, LOH)系某一特殊基因正常的两个成对等位基 因出现不同的基因组变化, 可作为癌前病变恶性转化的 早期预测指标 ${ }^{[13]}$. 研究表明, 染色体 $3 p 、 9 q 、 13 q$ 和 $17 p$ 中的 $\mathrm{LOH}$ 是口腔癌发生的早期征兆 ${ }^{[14]}$. 同样, 基因突 变存在于肿瘤发生的各个阶段，可涉及不同染色体上多 种基因的变化. Wang 等 ${ }^{[15]}$ 研究发现在 OSCC 患者中, 多 种唾液基因组生物标志物 $\left(\mathrm{TSP}_{53}\right.$ 、 $\mathrm{PIK} 3 \mathrm{CA}$ 、 CdkN2A/p16、FBXW7、HRAS 和 NRAS)会发生突变. 此 外, Cyclin D1 是细胞周期调控的重要调节因子, Cyclin D1 基因扩增与 OSCC 不良预后相关 ${ }^{[16]}$.

转录组：唾液中含有口腔局部组织的 RNA，因此唾 液转录组诊断亦是一种新颖的临床方法. 转录组由在特 定发育阶段或生理条件下存在于细胞中的所有编码和 非编码 RNA 组成. 而非编码 RNA 可进一步细分为微 RNA(microRNA)和长非编码 RNA. 在编码的 RNA 中, 李等 ${ }^{[17]}$ 发现 OSCC 患者唾液中 IL-8、H3F3A、IL-1 $\beta$ 、 S100 钙结合蛋白 P(S100P)、双特异性磷酸酶 1(DUSP1) 和亚精胺 N1-乙酰转移酶(SAT)的 mRNA 显著升高. 对 于非编码的 RNA, Park 等 ${ }^{[18]}$ 发现在唾液 microRNA 中 miR-125a 和 miR-200a 与口腔癌密切相关.

蛋白质组: 蛋白质在唾液组成中所占的比例较高. 唾液在口腔中经唾液腺不断分泌、更新，口腔黏膜细胞、 唾液腺和口腔微生物的变化都可通过唾液蛋白质分析

表 1 口腔癌相关唾液肿瘤生物标志物分类

Table 1 Classification of salivary tumor biomarkers associated with oral cancer

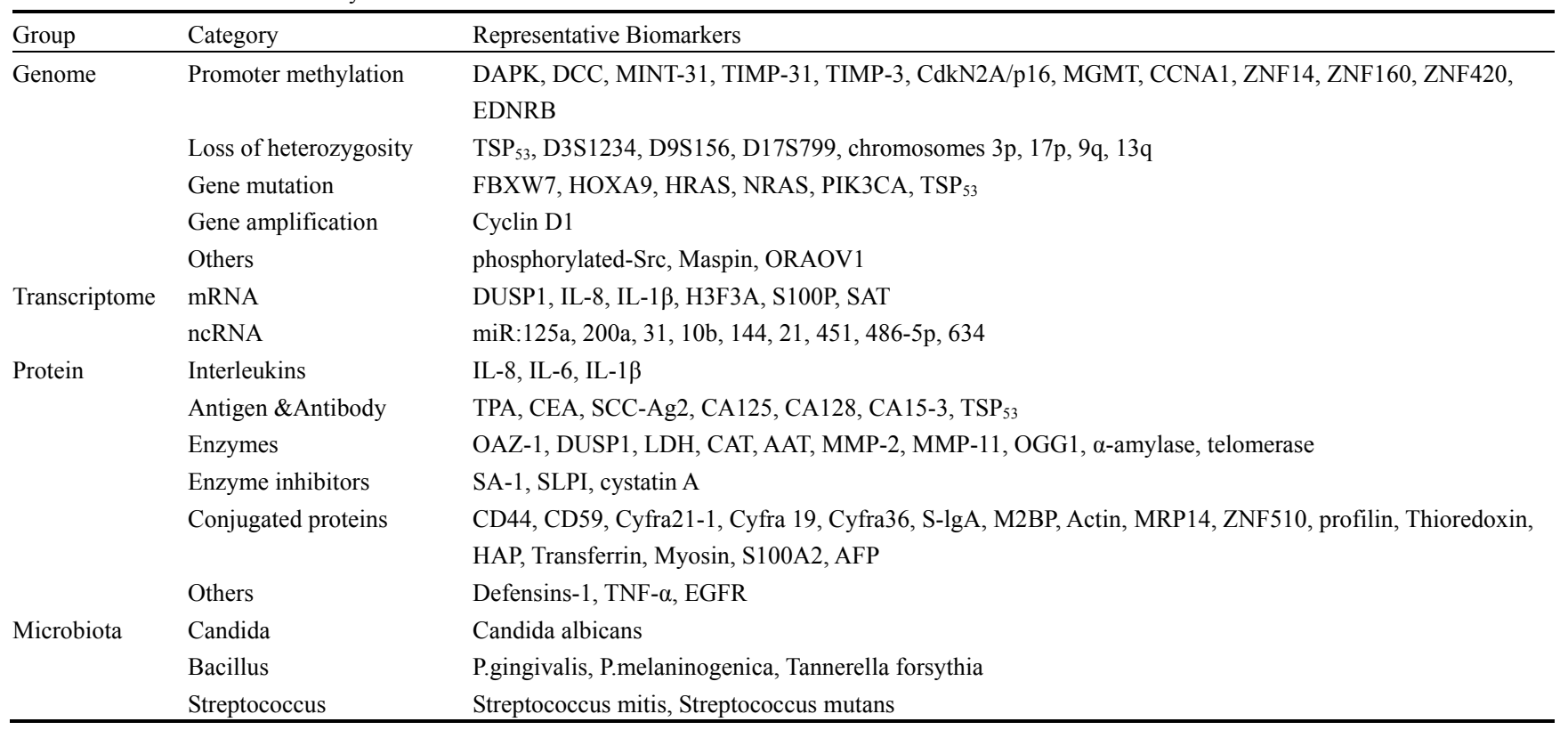


检测到. 唾液含有 2000 多种蛋白质, 可将其主要分为白 介素、抗原和抗体、酶、酶抑制剂和结合蛋白等这几大 类. John 等 ${ }^{[19]}$ 通过检测 32 名无疾病受试者和 19 名口腔 癌患者发现白介素中的 IL-6 和 IL-8 在口腔癌患者中的 含量较正常人显著增高. 抗原、抗体类的标志物有鳞状 细胞癌相关抗原 (SCC)、癌肧抗原(CEA)和组织多肽性抗 原(TPS)等. Nagler 等 ${ }^{[20]}$ 在 14 名癌症患者和 16 名健康对 照中分析检测获得患者唾液中 SCC、CEA、TPS 的含量 显著增加, 可用作 OSCC 诊断工具. 近些年, 唾液中的 部分酶和酶抑制剂也逐渐受到重视, 如 8-差基鸟嘌呤糖 基化酶 $(O G G 1)^{[21]}$ 和截短型半胱氨酸蛋白酶抑制剂 $(\mathrm{SA}-1)^{[22]}$ 可作为口腔癌的相关标志物来进行检测. 此

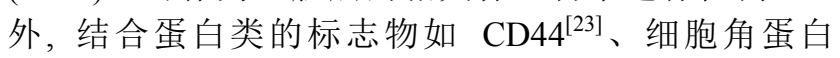
21-1(Cyfra21-1) $)^{[24]}$ 、肌动蛋白及肌球蛋白 ${ }^{[25]}$ 等对口腔癌 的诊断亦具有一定的参考价值.

微生物组: 饮食、药物、习惯和宿主免疫状态的某 些改变可能导致口腔微生物群的过度生长, 从而使该部 位易于发病. 常见的口腔致病菌按其形状可分为念珠 菌、杆菌和链球菌. Lim 等 ${ }^{[26]}$ 研究口腔微生物在肿瘤患 者和健康受试者唾液中的流行情况, 发现变异链球菌、 有核梭杆菌和白色念珠菌最为常见, 且可作为标志物来 检测口腔癌.

此外, 唾液中相对分子质量较小的代谢物也能间接 反映口腔癌相关基因和蛋白质的表达. 如 Sugimoto 等 ${ }^{[27]}$ 在牙周病患者唾液中发现 27 种标志性的代谢物, 在口腔癌患者唾液中发现了 28 种标志性的代谢物, 其 中聚胺、鸟氨酸和腐胺的水平明显升高; 而胆碱、甜菜 碱、哌啶酸和左旋肉碱在浓度上与健康人有显著的差异.

上述肿瘤生物标志物的获得与唾液的前处理密切 相关, 需较为规范的采集、处理和储存方法. 唾液采集 应考虑受试者、收集部位及方式 ${ }^{[28]}$. 一般在早晨无任何 进食、饮水和口腔卫生清洁行为前采集唾液 ${ }^{[29]}$, 采集的 部位包括唾液腺、龁沟液和粘膜渗出物 ${ }^{[30]}$, 有自然流取 法、吐取法、棉柱法、吸引法等采集方法 ${ }^{[31]}$. 唾液处理 多采用离心分离, 但处理时的离心力、温度和时间对目 标物的纯度有一定程度的影响; 且上述简单的处理只能 获得多种肿瘤生物标志物的混合物, 无法获得单一标志 物, 使后续的鉴定、检测难度较大. 一些唾液生物标志 物的半衰期非常短, 处理好的唾液样本可采用液氮冷藏 或添加酶抑制剂，延长保存时间.

近年来, 大量唾液肿瘤生物标志物被人们所发现, 关于其分析检测方法研究也取得了诸多进展. 以下就目 前国内外唾液肿瘤标志物现存常用检测方法进行概述 和比较.

\section{3 唾液肿瘤生物标志物常用检测方法}

尽管唾液具有自身优势, 但其实际使用中也存在着 很大的挑战. 唾液样品中肿瘤生物标志物的表达浓度比
血液低几个数量级，较难区分背景和目标特异性信号. 分析唾液肿瘤生物标志物时, 常规方法多采用灵敏度和 特异性这两个指标来衡量检测效果, 因此提供较高灵敏 度和特异性的方法是至关重要的. 根据唾液肿瘤生物标 志物种类的不同，有如下的几种常规检测方法，其中对 于蛋白质组的检测方法种类较多, 其他三组标志物的常 规检测方法相对较少.

\section{1 基因组的检测}

基因组检测的常规方法有基因测序和 PCR 分析. 基因测序能分析测定基因全序列; PCR 则是一种用于放 大扩增特定的 DNA 片段的分子生物学技术. Gaykalova 等 ${ }^{[32]}$ 采用基因测序的方法对原发性口腔癌表观遗传学 改变进行了全基因组分析, 结合癌症特异性异常值统计 数据确定了在口腔癌中基因甲基化的新型生物标志物 ZNF14 和 ZNF160, 并采用定量甲基化特异性 PCR 的方 法，分别显示出 $8.47 \%$ 和 $16.95 \%$ 的灵敏度. Schussel 等 ${ }^{[33]}$ 发现唾液中内皮素受体 $\mathrm{B}$ 型(EDNRB)启动子甲基 化是口腔癌前病变的生物标志物. 通过定量甲基化特异 性 PCR 在 191 位患者的唾液中分析 EDNRB 的甲基化状 态，分析结果的灵敏度达 $38 \%$. 基因测序和 PCR 技术可 以使检测的准确性提高, 对疾病的预防和治疗起着重要 的作用, 但是两者所需的仪器较为复杂, 检测成本较高.

\section{2 转录组的检测}

鉴定转录组肿瘤标志物的主要方法是定量 PCR 和 微阵列. 定量 PCR 是在 DNA 扩增反应中, 以苂光染剂 侦测每次聚合酶链锁反应循环后产物总量的技术; 而微 阵列是在固体表面上集成已知序列的基因探针，被测生 物细胞或组织中大量标记的核酸序列与上述探针阵列 进行杂交，通过检测相应位置杂交探针，实现基因信息 的快速检测. Hung 等 ${ }^{[34]}$ 采用定量 PCR 分析 20 个唾液样 品中的 miR-21 和 miR-31. 与对照组相比, 在口腔癌患 者中观察到唾液中 miR-21 和 miR-31 的表达显著增加 (分别为 $P=0.003$ 和 $P<0.001$ ). 谢等 ${ }^{[35]}$ 通过微阵列方法 将 6 种 miRNA(10b、144、21、451、486-5p 和 634)鉴 定为靶标. 经定量 PCR 验证后，其灵敏度分别为 $89.7 \% 、 92.3 \% 、 84.6 \% 、 79.5 \% 、 43.6 \%$ 和 $89.7 \%$, 特异 性分别为 $57.9 \% 、 47.4 \% 、 57.9 \% 、 57.9 \% 、 89.5 \%$ 和 $47.4 \%$. 实验结果可看出两种检测方法的特异性和灵敏度较高, 但是同样存在耗材贵、检测成本高和操作复杂的缺点.

\section{3 蛋白质组的检测}

检测蛋白质组标志物常用的检测方法可分为三大 类(见表 2).

(1)免疫方法: 主要是 ELISA 和免疫印迹法(western blotting,WB). 这些免疫技术通常受到交叉反应和高度 非特异性结合的影响, 且所使用的抗体相对昂贵, 因此 存在较大提升空间. Katakura 等 ${ }^{[36]}$ 通过 ELISA 检测了 20 名健康者和 19 名口腔癌患者唾液中细胞因子(IL-6、IL-8 
表 2 蛋白质组常用检测方法比较

Table 2 Comparison of common detection methods for proteome

\begin{tabular}{|c|c|c|c|c|c|c|c|}
\hline \multicolumn{2}{|c|}{ Common methods } & \multirow{2}{*}{$\begin{array}{l}\text { Biomarkers } \\
\text { IL-8, IL-6, IL-1 } \beta\end{array}$} & \multirow{2}{*}{$\begin{array}{l}\text { Sensitivity } / \% \\
80\end{array}$} & \multirow{2}{*}{$\frac{\text { Specificity } / \%}{43}$} & \multirow{2}{*}{$\begin{array}{l}\text { Advantages } \\
\text { Strong reliability, high detection } \\
\text { efficiency }\end{array}$} & \multirow{2}{*}{$\begin{array}{l}\text { Disadvantages } \\
\text { Time consuming, pro- } \\
\text { gram complex, high }\end{array}$} & \multirow{2}{*}{$\frac{\operatorname{Ref}}{[36]}$} \\
\hline $\begin{array}{l}\text { Immune } \\
\text { methods }\end{array}$ & ELISA & & & & & & \\
\hline & & MMP-9 & 90 & 79 & & $\cos t$ & [44] \\
\hline & & TPS & 69 & 87 & & & [20] \\
\hline & & M2BP & 74 & 40 & & & [45] \\
\hline & & CEA, SCC & 81 & 77.8 & & & [46] \\
\hline & WB & CD44 & $62 \sim 70$ & $75 \sim 88$ & Large analysis capacity, high & Complicated operation, & [37] \\
\hline & & profilin & 90 & 83 & sensitivity, strong specificity & high cost & [47] \\
\hline & & $\begin{array}{l}\text { MRP14, CD59, } \\
\text { CAT }\end{array}$ & - & - & & & {$[38]$} \\
\hline & & Cyfra 21-1 & 84 & 93 & & & [48] \\
\hline & & $\mathrm{LDH}$ & 79 & 42 & & & [44] \\
\hline \multirow{6}{*}{$\begin{array}{l}\text { Mass } \\
\text { spectrometry }\end{array}$} & LC-MS & $\mathrm{S} 100 \mathrm{~A} 2, \mathrm{ggG}$ & 95 & 86 & nology & & [39] \\
\hline & & Transferrin & & & & & \\
\hline & MALDI-MS & Thioredoxin, & 70.8 & 70.8 & & & [40] \\
\hline & & ZNF510 & 95 & 95 & & & \\
\hline & 2-DE-MS & HAP, AAT & - & - & & & [41] \\
\hline & iTRAQ-MS & Myosin, Actin & $67 / 100$ & $75 / 83$ & & & {$[50]$} \\
\hline \multirow[t]{2}{*}{$\begin{array}{l}\text { Optical } \\
\text { methods }\end{array}$} & SERS & SA & 94 & 98 & $\begin{array}{l}\text { Simple operation, fast detection } \\
\text { speed, high sensitivity }\end{array}$ & $\begin{array}{l}\text { Complicated operation, } \\
\text { large background inter- } \\
\text { ference }\end{array}$ & [42] \\
\hline & IF & LP & - & - & $\begin{array}{l}\text { Strong specificity, high sensitiv- } \\
\text { ity, fast speed }\end{array}$ & Program complex & {$[33]$} \\
\hline
\end{tabular}

和 IL-1 $\beta$ )的水平，检测方法的灵敏度为 $80 \%$, 特异性为 $43 \%$. 在口腔癌患者中 3 种细胞因子的表达均高于健康 对照组, IL-6 差异最显著. Franzmann 等 ${ }^{\left[{ }^{[37}\right]}$ 采用 WB 验证 了 CD44 与区分恶性和良性病变的强关联性. 此外, $\mathrm{Hu}$ 等 ${ }^{[38]}$ 在 OSCC 患者的唾液中, 采用 WB 发现了细胞角蛋 白 19 片段(Cyfra21-1)、CD59 和过氧化氢酶(CAT)三种 标志物.

(2)与质谱 (mass spectrometry, MS)相关的方法: 质 谱技术、质谱-其它检测技术, 已成功在唾液中鉴定出多 种蛋白质标志物. 如 Dowling 等 ${ }^{[39]}$ 采用液相色谱-质谱 联用(LC-MS) 方法检测出口腔癌患者唾液中转铁蛋白、 免疫球蛋白重链恒定区 (IgG)及 S100 钻结合蛋白. 此外, Jou 等 ${ }^{[40]}$ 将基质辅助激光解吸电离(matrix-assisted laser desorption ionization, MALDI)与 MS 联用来检测唾液中 锌指蛋白 510 肽(ZNF510), 通过分析来自 OSCC 患者 $(n=47)$ 和健康人 $(n=30)$ 的 77 个唾液样品, 可鉴定 ZNF510 作为早期检测 OSCC 的唾液生物标志物, 检测 的灵敏度和特异性均为 $95 \%$. Jessie 等 ${ }^{[41]}$ 从 12 名 OSCC 患者和健康受试者的二维凝胶电泳 (two-dimensional electrophoresis，2-DE)唾液蛋白质谱中发现二者的差异 明显, 患者唾液 $\alpha$-抗胰蛋白酶(AAT)和触珠蛋白(HAP) $\beta$
链被分解为具有微观异质性的多肽斑点，以此可鉴定其 为潜在生物标志物以改善癌症的检测.

(3)光学分析法: 主要采用表面增强拉曼散射 (surface enhancement of Raman scattering, SERS)和免疫 苂光 (immunofluorescence, IF)的方法来对唾液中的标志 物进行检测. Hernández-Arteaga 等 ${ }^{[42]}$ 采用 SERS 检测 100 名癌症患者和 106 名健康人唾液, 结果显示检测方法的 灵敏度为 $94 \%$, 特异度为 $98 \%$. 由此表明 SERS 技术可 作为一种简单方便、高灵敏的唾液酸(SA)定量分析方法. Schapher 等 ${ }^{[43]}$ 通过使用免疫荧光技术发现在所有唾液 腺肿瘤中, 瘦素(LP)的表达量远高于健康的腮腺组织. 这些方法虽然灵敏度高、特异性强; 但操作复杂、背景 干扰较大.

\section{4 微生物组的检测}

微生物组中的肿瘤标志物常见的检测方法为 PCR. Mager 等 ${ }^{[51]}$ 使用 PCR 方法来评估口腔鳞状细胞癌患者 和健康受试者唾液中的口腔微生物群, 发现牙龈卟啉单 胞菌、产黑色素普雷沃菌和平滑肌链球菌三种微生物群 组合的水平显著升高，具有 $80 \%$ 的灵敏度和 $82 \%$ 的特异 性, 从而表明唾液中微生物群作为口腔癌辅助诊断指标 的作用. 
就目前国内外现存唾液肿瘤生物标志物常规检测 方法的相关报道, 笔者认为在灵敏度、速度及检测成本 方面仍有广阔的发展空间. 因此, 开发高效准确、快速 简便的唾液肿瘤标志物检测新方法, 对口腔癌人群同步 笁查与检测, 口腔癌病情、病程变化跟踪监护, 进而实 施针对性干预与治疗具有重要意义. 以下根据检测目标 物质的不同, 重点阐述几类新型电化学生物传感方法 (包括 DNA、RNA、蛋白质和微生物等)在唾液肿瘤标志 物检测方面的相关应用与最新研究进展.

\section{4 电化学生物传感方法}

化学生物传感方法是利用生物活性材料(如酶、蛋 白、抗体及核酸等)作为识别元件, 将生化反应转变成可 定量的物理、化学信号, 从而能够进行生命、化学物质 检测和监控的高新技术. 由于仪器设备简单、选择性好、 灵敏度高、响应快速、成本低及不受样品颜色和浊度的 影响等突出特征, 电化学生物传感器(换能器为电化学 电极) 是目前研究唾液肿瘤标志物最具潜力的一种快速 简便的新型方法. 由于电化学生物传感器能进行痕量检 测，常采用检测范围、检测限来评价其分析性能. 根据 检测靶标的数量、类别的不同, 本文对近几年检测唾液 肿瘤生物标志物的电化学方法进行简要评述.

\section{1 单靶标检测}

选取某一种标志物进行传感检测, 即为单靶标分析 法. 其识别元件针对性地与靶标结合, 特异性较强, 干 扰较小, 且针对单靶标的传感策略也相对简单. 鉴于唾 液中肿瘤生物标志物分类的不同，以下小节重点介绍了 一些用于单独检测唾液中四类标志物的电化学生物传 感方法.

\subsection{1 基因组}

对于基因组的检测, 电化学生物传感器多需在电极 表面进行 DNA 固定. CdkN2A/p16 基因作为细胞周期调 控的参与者, 与口腔癌的发展和恶化密切相关. 我们课 题组对其做了大量的检测研究工作. 如图 1A 所示 ${ }^{[52]}$, 将电纺纳米纤维尼龙 6-多壁碳纳米管修饰在 GC 电极表 面, 通过电沉积 $\mathrm{SiO}_{2}$ 获得功能电纺纳米纤维 (PA6-MWCNTs-SiO 2 ), 将其进一步氨基化并经戊二醛 (GA) 共价偶联 $\mathrm{NH}_{2}$ 修饰的 ssDNA1. ssDNA1 修饰电极 与 $\mathrm{CdkN} 2 \mathrm{~A} / \mathrm{p} 16$ 基因、 $\mathrm{Ru}(\mathrm{bpy})_{3}{ }^{2+} / \mathrm{c}^{2}$ 纳米粒子掺杂金的 合金核壳光学复合纳米颗粒标记 ssDNA2(RuAg@AuNPs-ssDNA2)进行杂交反应, 通过 电致化学发光 $(\mathrm{ECL})$ 进行定量检测. 该传感器的检测范 围为 $1.0 \times 10^{-3} \sim 1.0 \mathrm{pmol} \cdot \mathrm{L}^{-1}$, LOD 为 $0.5 \mathrm{fmol} \cdot \mathrm{L}^{-1}$. 课 题组的 Wang 等 ${ }^{[53]}$ 基于功能化的糊状纳米纤维复合物 (PG/GR/CS/PPy)修饰 SPCE、RuAg@AuNPs 标记 DNA 放大检测信号，构建一种通用的三明治型 ECL 生物传 感器, 实现对 $\mathrm{CdkN} 2 \mathrm{~A} / \mathrm{p} 16$ 基因的特异性检测, 检测范
围在 $1.0 \times 10^{-4} \sim 1.0 \mathrm{nmol} \cdot \mathrm{L}^{-1}$, LOD 为 $5.0 \times 10^{-2} \mathrm{pmol} \bullet$ $\mathrm{L}^{-1}$.
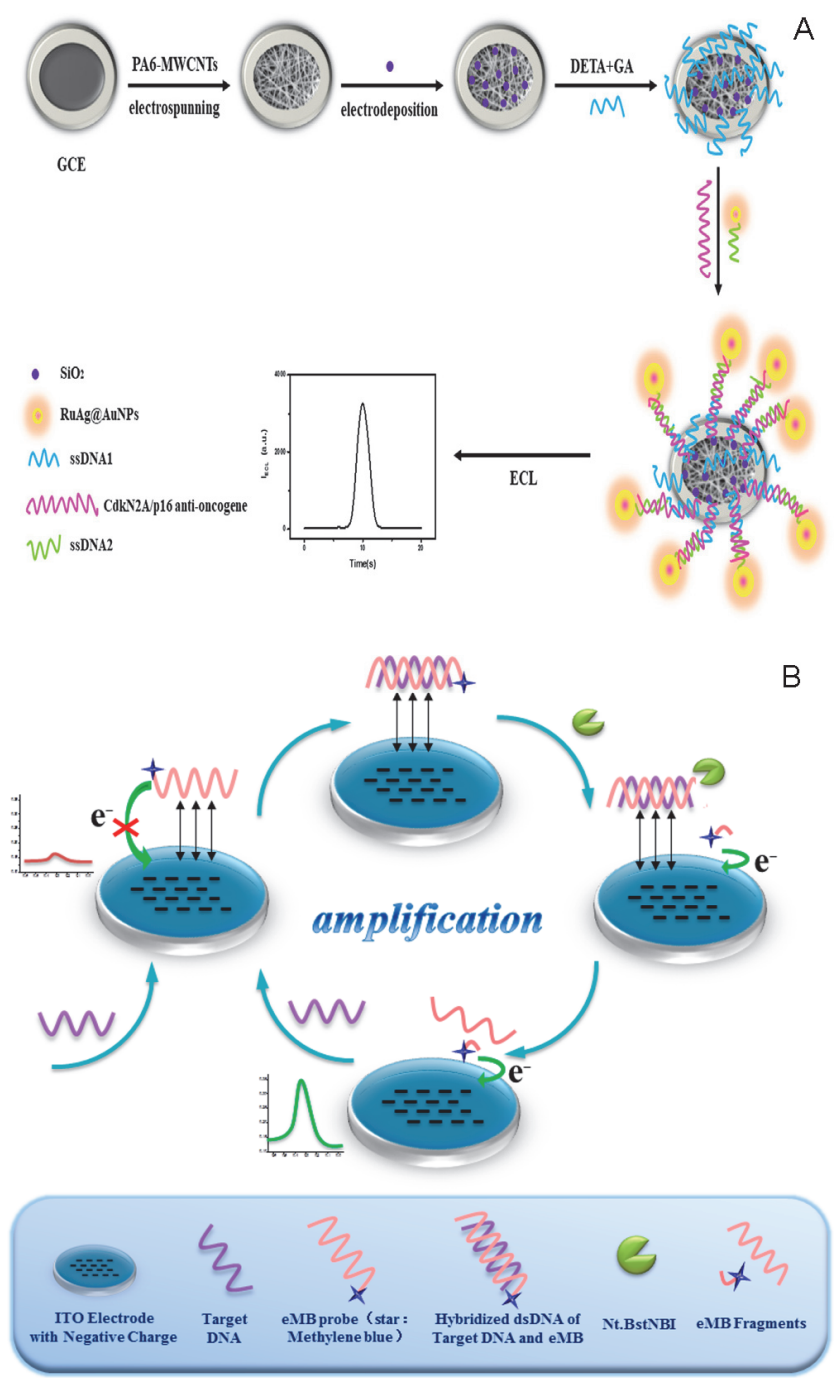

图 1 (A) 基于功能电纺纳米纤维和核壳发光复合纳米粒子的 CdkN2A/p16 基因 ECL 生物传感器 ${ }^{[52]}$; (B)基于 Nicking 内切酶信号放 大的 ORAOV1 电化学传感器 ${ }^{[5]}$

Figure 1 (A) CdkN2A/P16 gene ECL biosensor based on functional electrospun nanofibers and core-shell luminescent composite nanoparti$\operatorname{cles}^{[52]}$; (B) ORAOV1 electrochemical sensor based on Nicking endonuclease signal amplification ${ }^{[54]}$

Tan 等 ${ }^{[54]}$ 基于 Nicking 核酸内切酶信号放大电化学 方法, 测定唾液中口腔癌过度表达序列 1(ORAOV1), 如图 1B. 在 3'末端由亚甲蓝标记的含有 20 个碱基的 DNA 链(eMB), 具有简单的不对称序列，可被 Nicking 核酸内切酶识别. 在没有靶 DNA 的情况下, eMB 不能被 Nicking 核酸内切酶识别, 酶切反应不能进行. eMB 虽可 在电极上被检测到，但由于带负电 ITO 电极的强静电排 斥, 其产生的电化学响应可被忽略. 在靶 DNA 存在下, eMB 与靶 DNA 杂交形成双链结构, 可以通过 Nicking 核酸内切酶识别并分解为两部分, 一部分包含 18 个碱 基的长链 DNA; 另一个包含 2 个碱基的短链 DNA. 短 链 DNA 与 MB 连接, 其易扩散到 ITO 电极表面, 从而 
检测到强的 DPV 响应. 检测同时, 靶 DNA 可以与双链 DNA 解离并触发下一轮杂交、切割和释放. 通过这种方 式, 单个靶 DNA 可多次重复触发链断裂循环并实现信 号放大. 该传感器 $\mathrm{LOD}$ 为 $0.35 \mathrm{pmol} \cdot \mathrm{L}^{-1}$, 并成功应用于 检测添加在人造唾液样品中的靶 DNA, 回收率为 $99.4 \% \sim 101.7 \%$.

\subsection{2 转录组}

转录组的研究主要集中在从细胞分泌及各种来源 进入口腔的 mRNA 和 miRNA(如表 3).

Wang 等 ${ }^{[57]}$ 构建使用电磁控制的金电极(AuE)测定 口腔癌相关 miRNA(hsa-miR-200a)的计时电流传感器, 如图 2. 捕获探针 $(\mathrm{Cp}$, 黑色)其一端用生物素官能化, 并 固定在链霉亲和素修饰的磁珠(Strep-MB)上; 信号探针 (Sp, 绿色)两端用生物素修饰. 在没有靶 $\operatorname{miRNA}(\mathrm{T}$, 红 色)的情况下, 由于温度较低, $\mathrm{Cp}$ 和 $\mathrm{Sp}$ 不会杂交. 然而, 在靶 miRNA(T)存在下, $\mathrm{Cp}$ 可与 $\mathrm{T} 、 \mathrm{Sp}$ 同时杂交, 并在 $\mathrm{MB}$ 的表面上形成“Y”结构的杂交体. 附着杂交体的 MB 可通过生物素化的 $\mathrm{Sp}$ 捕获链霉亲和素标记的 HRP(Strep-HRP). 通过在电线圈上添加电压, 将 MB 吸 附在电磁可控工作电极表面, 在四甲基联苯胺-过氧化 氢( $\left(T M B-\mathrm{H}_{2} \mathrm{O}_{2}\right)$ 溶液中, $\mathrm{HRP}$ 修饰的 $\mathrm{MB}$ 具有强过氧化物 酶活性, 可有效催化 $\mathrm{H}_{2} \mathrm{O}_{2}$ 介导的 TMB 氧化, 导致其电 流信号增加. 此传感平台可检测低至 $0.22 \mu \mathrm{mol} \cdot \mathrm{L}^{-1}$ 的 目标 miRNA, 其成功地应用于分析不同浓度的靶 miRNA 的唾液样品, 回收率为 $93 \% \sim 108 \%$.

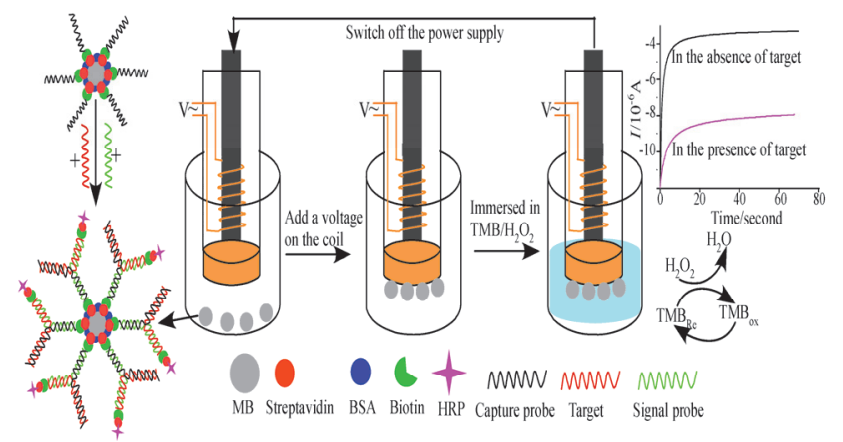

图 2 磁控电化学 RNA 传感器 ${ }^{[57]}$

Figure 2 Magnetron electrochemical RNA sensor ${ }^{[57]}$

\subsection{3 蛋白质组}

近几年, 电化学传感器已广泛用于唾液中蛋白质类 肿瘤标志物的检测(如表 4). Aydin 等 ${ }^{[64]}$ 建立基于 6-膦酰 基已酸(PHA)修饰 ITO 电极的无标记阻抗 IL-8 免疫传感 器. ITO 电极先后与 $\mathrm{NH}_{4} \mathrm{OH} 、 \mathrm{PHA}$ 溶液作用, 形成含有
羧基的单层膜; 经 $\mathrm{EDC} / \mathrm{NHS}$ 将羧基活化并共价连接捕 获抗体 IL-8，捕获抗体 IL-8 进一步结合 IL-8 抗原; 在铁 氰化钾溶液中, 采用 EIS 对 IL-8 抗原定量检测. 该传感 器的检测范围在 $0.02 \sim 3 \mathrm{pg} \cdot \mathrm{mL}^{-1}$, LOD 为 $6 \mathrm{fg} \bullet \mathrm{mL}^{-1}$; 其与 ELISA 方法对唾液样品中 IL-8 的测定具有较好的 一致性.

Verma 等 ${ }^{[65]}$ 制备一种基于金纳米颗粒-还原氧化石 墨烯(AuNPs-rGO)复合材料的电化学免疫传感器, 用于 非侵入性检测唾液生物标志物 IL-8. 如图 3B 所示, 将 AuNPs-rGO 修饰 ITO 经 EDC/NHS 活化并固载 IL-8 抗 体, IL-8 抗体进一步结合 IL-8 抗原, 获得复合物修饰电 极; 在 Zobell 溶液中, 采用 DPV 检测复合物修饰电极的 电信号. 该传感器的检测范围在 $500 \mathrm{fg} \cdot \mathrm{mL}^{-1}$ 至 $4 \mathrm{ng} \cdot$ $\mathrm{mL}^{-1}, \mathrm{LOD}$ 为 $72.73 \pm 0.18 \mathrm{pg} \cdot \mathrm{mL}^{-1}$, 同时其对人唾液样 品中 IL-8 的检测表现出极好的特异性. 此外, 该传感器 长达 3 个月的可重复使用性和稳定性证明了该纳米平台 用于检测临床相关的其他生物标记物的商业潜力.

$\mathrm{Li}$ 等 ${ }^{[58}$ 报道基于碱基堆积依赖性 DNA 杂交的电化 学蛋白质传感平台, 如图 4A. 首先将硫醇化的捕获探 针固定在金电极上，接着用一对短的互补寡 DNA 标记 识别甲胎蛋白(AFP)不同表位的一对抗体，其中 DNA2 与捕获探针互补, 且 $3^{\prime}$ 末端标记亚甲蓝(MB). 在 AFP 存 在下，抗体对(AFP-Y1 和 AFP-Y2)将同时与 AFP 的不同 表位结合, 抗体偶联的寡 DNA(DNA1 和 DNA2)将杂交 形成发夹. 随后 DNA2 的 3'末端序列的其余部分可与捕 获探针杂交，因为碱基堆积带来额外的稳定性，导致标 记在 DNA2 上的 MB 被拉近电极表面, 从而产生氧化还 原电流. 在没有 AFP 的情况下, 互补的抗体-DNA 对、 MB 标记的 DNA-捕获探针对不能稳定杂交, MB 远离电 极表面, 阻碍电子转移, 仅观察到背景电流. 该传感器 可检测到低至 $2.0 \mathrm{pg} \cdot \mathrm{mL}^{-1}$ 的甲胎蛋白. 此外, 采用该传 感器和 ELISA 方法对实际唾液样本进行检测, 二者所 得结果基本吻合. Chen 等 ${ }^{[72]}$ 设计一种基于适体链置换 反应的检测上皮细胞粘附分子(EpCAM)的电化学生物 传感器(图 4B). 5'端 SH 修饰的发夹探针 1(Hp1)经 $\mathrm{Au}-\mathrm{S}$ 键固载在 $\mathrm{Au}$ 电极上. 探针 $\mathrm{A}$ 与 $\mathrm{EpCAM}$ 适体杂交形成 适体一探针 A 双链体. 在无 EpCAM 的情况下, 链置换反 应的发生受到限制，仅产生可忽略的电流信号. 加入 EpCAM 后, 探针 A 从适体-探针 A 双链体中释放出来, 与 $\mathrm{Hp} 1$ 杂交后打开其发夹结构, Hp1 进一步与 MB 标记 发夹探针 2(Hp2)杂交，形成 Hp1-Hp2 双链体，MB 富集 于金电极表面，经方波伏安法检测其电流响应. 另外， 解离的探针 $\mathrm{A}$ 可与另一 Hp1 杂交以开始下一轮 DNA 再

表 3 转录组电化学传感器比较

Table 3 Comparison of transcriptome electrochemical sensors

\begin{tabular}{|c|c|c|c|c|c|}
\hline Method & Electrode & Biomarker & Detection range & LOD & Ref. \\
\hline $\mathrm{CA}$ & Strep-Au array & IL-8 mRNA & $5 \sim 50 \mathrm{nmol} \cdot \mathrm{L}^{-1}$ & $0.4 \mathrm{fmol} \cdot \mathrm{L}^{-1}$ & [55] \\
\hline Amperometry & DNA-dendrimer/DDPpy modified Au array & IL-8 mRNA & - & $10 \mathrm{amol} \cdot \mathrm{L}^{-1}$ & {$[56]$} \\
\hline $\mathrm{CA}$ & Strep-MBs coupled to Au electrode & miR-200a & $1 \mathrm{amol} \cdot \mathrm{L}^{-1} \sim 10 \mathrm{fmol} \cdot \mathrm{L}^{-1}$ & $0.22 \mathrm{amol} \cdot \mathrm{L}^{-1}$ & [57] \\
\hline
\end{tabular}


表 4 蛋白质组电化学传感器比较

Table 4 Comparison of proteome electrochemical sensors

\begin{tabular}{|c|c|c|c|c|c|}
\hline Method & Electrode & Biomarker & Detection range & LOD & References \\
\hline DPV & MB-DNA-antibody chimeras-AuE & AFP & $2.0 \mathrm{pg} \cdot \mathrm{mL}^{-1} \sim 20.0 \mathrm{ng} \cdot \mathrm{mL}^{-1}$ & $2.0 \mathrm{pg} \cdot \mathrm{mL}^{-1}$ & [58] \\
\hline DPV & GO/ITO & hTERT & $10 \mathrm{ag} \cdot \mathrm{mL}^{-1} \sim 50 \mathrm{ng} \cdot \mathrm{mL}^{-1}$ & $10 \mathrm{ag} \cdot \mathrm{mL}^{-1}$ & [59] \\
\hline Amperometry & HOOC-MBs coupled to SPCE & IL-6 & $1.75 \sim 500 \mathrm{pg} \cdot \mathrm{mL}^{-1}$ & $0.39 \mathrm{pg} \cdot \mathrm{mL}^{-1}$ & [60] \\
\hline DPV & ProtG-MBs coupled to SPCE & GHRL & $10^{-3} \sim 10^{3} \mathrm{ng} \cdot \mathrm{mL}^{-1}$ & $7 \mathrm{pg} \cdot \mathrm{mL}^{-1}$ & [61] \\
\hline DPV & $\mathrm{ZrO}_{2}-\mathrm{RGO} / \mathrm{ITO}$ & CYFRA-21-1 & $2 \sim 22 \mathrm{ng} \cdot \mathrm{mL}^{-1}$ & $0.122 \mathrm{ng} \cdot \mathrm{mL}^{-1}$ & [62] \\
\hline EIS & $\mathrm{Fe}_{3} \mathrm{O}_{4} @ \mathrm{Au} \mathrm{NPs} / \mathrm{BDD}$ & IL-8 & $0.1 \sim 1000 \mathrm{pg} \cdot \mathrm{mL}^{-1}$ & $0.03 \mathrm{pg} \cdot \mathrm{mL}^{-1}$ & [63] \\
\hline EIS, CV & PHA/ITO & IL-8 & $0.02 \sim 3 \mathrm{pg} \cdot \mathrm{mL}^{-1}$ & $6 \mathrm{fg} \cdot \mathrm{mL}^{-1}$ & [64] \\
\hline DPV & AuNps-rGO/ITO & IL-8 & $500 \mathrm{fg} \cdot \mathrm{mL}^{-1} \sim 4 \mathrm{ng} \cdot \mathrm{mL}^{-1}$ & $72.73 \mathrm{pg} \cdot \mathrm{mL}^{-1}$ & [65] \\
\hline EIS, CV & P3-TMA/ITO & IL- $1 \beta$ & $0.01 \sim 3 \mathrm{pg} \cdot \mathrm{mL}^{-1}$ & $3 \mathrm{fg} \cdot \mathrm{mL}^{-1}$ & [66] \\
\hline EIS & L-cysteine-AuE & CD59 & $1 \sim 1000 \mathrm{fg} \cdot \mathrm{mL}^{-1}$ & $0.38 \mathrm{fg} \cdot \mathrm{mL}^{-1}$ & [67] \\
\hline DPV & Serine-nZrO $2 / \mathrm{ITO}$ & CYFRA-21-1 & $0.01 \sim 29 \mathrm{ng} \cdot \mathrm{mL}^{-1}$ & $0.01 \mathrm{ng} \cdot \mathrm{mL}^{-1}$ & [68] \\
\hline $\mathrm{CV}$ & $\mathrm{APTES} / \mathrm{ZrO}_{2} / \mathrm{ITO}$ & CYFRA-21-1 & $2 \sim 16 \mathrm{ng} \cdot \mathrm{mL}^{-1}$ & $0.08 \mathrm{ng} \cdot \mathrm{mL}^{-1}$ & [69] \\
\hline Amperometry & SPEC & $\alpha$-amylase & $100 \sim 1200 \mathrm{U} \cdot \mathrm{mL}^{-1}$ & $1.1 \mathrm{U} \cdot \mathrm{mL}^{-1}$ & [70] \\
\hline EIS & P3/ITO & $\mathrm{TNF} \alpha$ & $0.01 \sim 2 \mathrm{pg} \cdot \mathrm{mL}^{-1}$ & $3.7 \mathrm{fg} \cdot \mathrm{mL}^{-1}$ & [71] \\
\hline SWV & $\mathrm{MCH} / \mathrm{Hp} 1 / \mathrm{AuE}$ & ЕpCAM & $0.1 \sim 20 \mathrm{ng} \cdot \mathrm{mL}^{-1}$ & $20 \mathrm{pg} \cdot \mathrm{mL}^{-1}$ & [72] \\
\hline $\mathrm{CV}$ & DTSP-IDEs & Cortisol & $10 \mathrm{pg} \cdot \mathrm{mL}^{-1} \sim 100 \mathrm{ng} \cdot \mathrm{mL}^{-1}$ & $10 \mathrm{pg} \cdot \mathrm{mL}^{-1}$ & [73] \\
\hline EIS & (1D)-ZnO-NRs or(2D)-ZnO-NFs on AuE & Cortisol & - & $1 \mathrm{pmol} \cdot \mathrm{L}^{-1}$ & [74] \\
\hline EIS, CV & GP-PS67-b-PAA27/Au-ID $\mu$ Es & Cortisol & $3 \mathrm{pg} \cdot \mathrm{mL}^{-1} \sim 10 \mu \mathrm{g} \cdot \mathrm{mL}^{-1}$ & $3 \mathrm{pg} \cdot \mathrm{mL}^{-1}$ & [75] \\
\hline
\end{tabular}

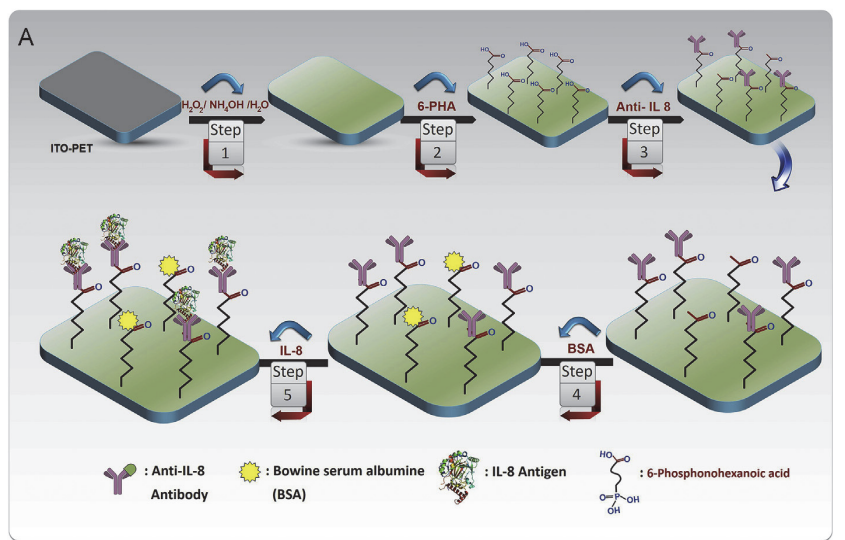

B

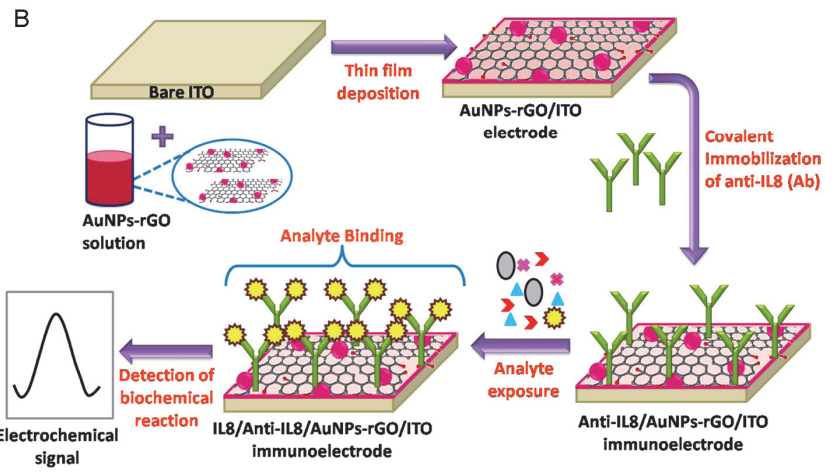

图 3 用于检测 IL-8 的电化学传感器. (A)以 PHA 为固定基质 ${ }^{[6]}$; (B) 基于 AuNPs-rGO 修饰电极 ${ }^{[65]}$

Figure 3 Electrochemical sensor for detecting IL-8. (A) Based on PHA as a fixed substrate ${ }^{[64]}$; (B) Modified electrode based on AuNPs-rGO ${ }^{[65]}$

循环扩增反应. 该传感器 $\mathrm{LOD}$ 为 $20 \mathrm{pg} \cdot \mathrm{mL}^{-1}$, 成功应用 于加标人血清、尿液和唾液中 EpCAM 的测定, 回收率 在 $93.2 \% \sim 95.6 \%$.
我们课题组 ${ }^{[76]}$ 报道有关肿瘤抑制蛋白 $\mathrm{TSP}_{53}$ 的电化 学检测. 将 MWCNTs 掺杂壳聚糖(CTS)纳米纤维, 通过 原位电沉积在其表面修饰 AuNPs 获得功能电纺纳米纤 维(MWCNTs-CTS-AuNP)修饰电极并固载 $\mathrm{TSP}_{53}$ 捕获抗 体. $\mathrm{TSP}_{53} 、 \mathrm{Ru}(\mathrm{bpy})_{3}{ }^{2+} / \mathrm{AgNPs}$ 掺杂二氧化硅核壳复合纳 米粒子 $\left(\mathrm{RuAg} / \mathrm{SiO}_{2} \mathrm{NPs}\right)$ 标记检测抗体经夹心免疫反应 进一步固载在修饰电极上. 由 $\mathrm{RuAg} / \mathrm{SiO}_{2} \mathrm{NPs}$ 的 ECL 信 号间接定量 $\mathrm{TSP}_{53}$, 其 $\mathrm{LOD}$ 为 $0.5 \mathrm{pg} \cdot \mathrm{mL}^{-1}$.

\subsection{4 微生物组}

口腔是细菌和其他微生物的栖息地, 一系列实验结 果表明口腔内环境失调可导致口腔疾病, 因此 Ahmed 等 ${ }^{[77]}$ 构建一种用于检测唾液中化脓性链球菌 (S.pyogenes)的新型免疫传感器. 如图 5 所示, 首先将聚 酪胺(Ptyr)电沉积到丝网印刷金电极上, 将生物素-亲和 素这一复合物与 Ptyr 上的胺基结合, 接着将生物素标记 的化脓性链球菌抗体与亲和素缀合, 采用 CV 和 EIS 方 法在铁氰化钾溶液中检测。该传感器能在 $50 \%(V / V)$ 唾 液中成功检测到 S.pyogenes, 检测范围为每 $10 \mu \mathrm{L}$ 含有 100 至 $10^{5}$ 个细菌, 具有良好的选择性和低交叉反应性.

\section{2 双靶标检测}

目前，口腔癌中单一性肿瘤生物标志物检测的敏感 性和特异性均十分有限. 不同的肿瘤既能具有不同的肿 瘤标志物, 也能具有共同的肿瘤标志物. 而同一种肿瘤 由于组织类型不同, 也可有一种或几种肿瘤标志物. 就 某一项肿瘤生物标志物而言，它对不同种类、不同类型 肿瘤的诊断价值也各不相同. 鉴于现有单一唾液肿瘤生 物标志物的敏感性和特异性不够理想, 难以准确反映口 腔癌的复杂性. 根据口腔癌的特性, 合理选择多种唾液 


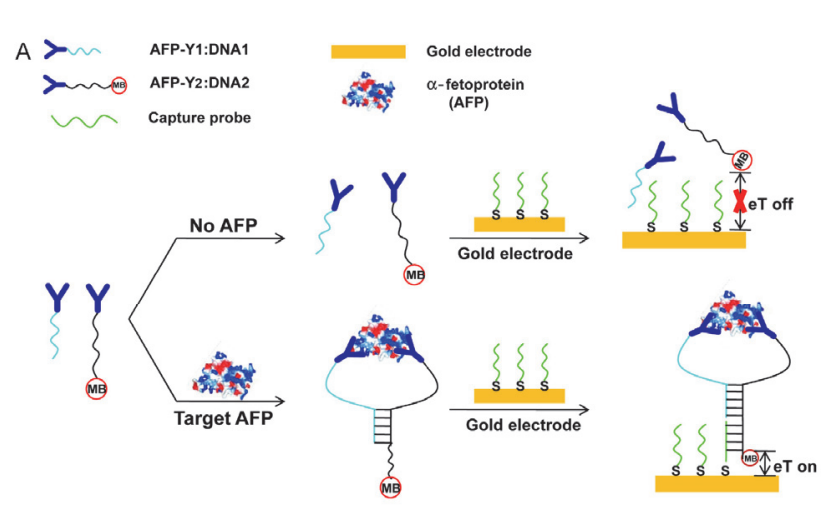

B
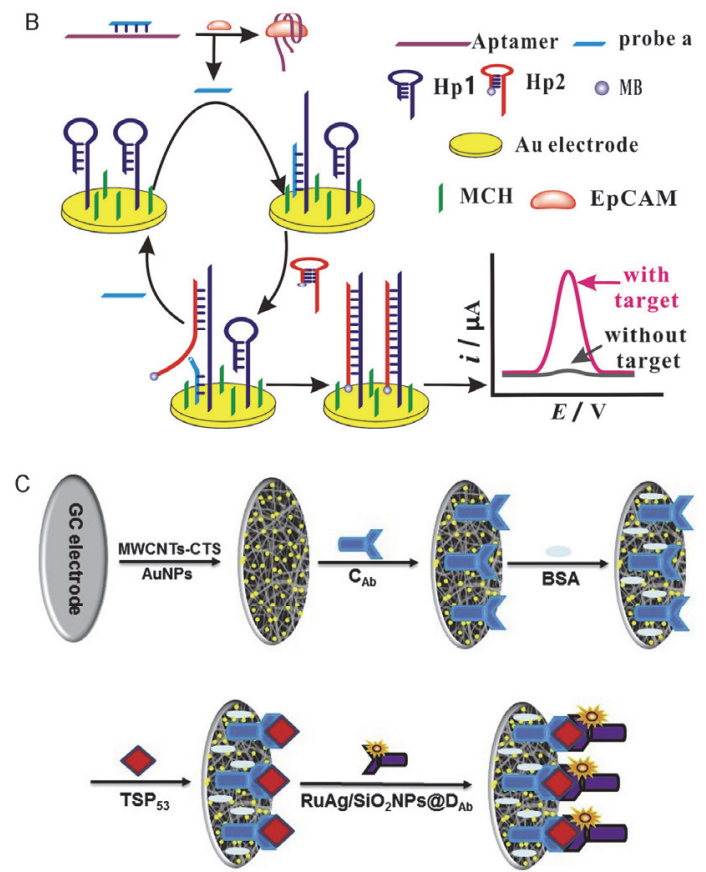

图 4 (A)基于碱基堆积依赖性 DNA 杂交的电化学传感器用于检测 $\mathrm{APF}^{[58]}$; (B)基于适体识别的电化学传感器用于检测 $\mathrm{EpCAM}^{[72]}$; (C)基 于电纺纳米纤维的 $\mathrm{ECL}$ 免疫传感器用于检测 $\mathrm{TSP}_{53}$ 蛋白 ${ }^{[76]}$

Figure 4 (A) Electrochemical sensor based on base stack-dependent DNA hybridization for detecting $\mathrm{APF}^{[58]}$; (B) Electrochemical sensor based on aptamer recognition for detecting $\operatorname{EpCAM}^{[72]}$; (C) Electrospun nanofiber-based ECL immunosensor for detecting $\mathrm{TSP}_{53} \operatorname{protein}^{[76]}$

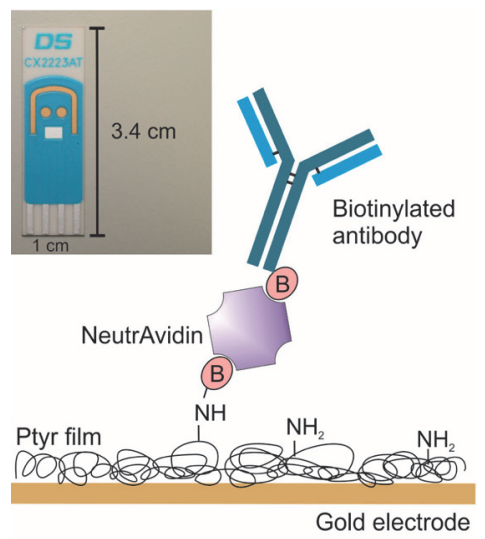

图 5 基于生物素-亲和素的电化学传感器用于检测 S.pyogenes ${ }^{[77]}$ Figure 5 Electrochemical sensor based on biotin-avidin for detection of S.pyogenes ${ }^{[77]}$
肿瘤生物标志物进行联合检测是显著提高其总检出率 及临床诊断价值的有效方法. 目前, 用于唾液样品中两 种肿瘤生物标志物(双靶标)的电化学传感平台已被报 道.

\subsection{1 组内双靶标}

通过在同一组别内进行双靶标的检测，可缩短分析 时间, 减小样品体积, 提高检测效率和降低成本; 还可 更好地发现两者之间的联系及其对检测结果的影响. 组 内双靶标的检测主要在基因组和蛋白质组中较为常见 (见表 5).

（1）基因组：魏研究小组 ${ }^{[78]}$ 构建一种基于电场诱导 释放和测量(EFIRM)技术的电化学传感器, 直接检测唾 液样品中表皮生长因子受体(EGFR)基因的突变，如图 6. 该传感器针对 EGFR 两种突变设计两套成对探针, 即 用于 EGFR 中外显子 19 缺失、L858R 突变的检测探针 和捕获探针. 首先通过施加循环方波电场, 将捕获探针 与吡咯共聚到 16 个裸金电极芯片上; 捕获探针与目标 物、异硫氰酸荧光素标记的检测探针杂交; 在酪蛋白磷酸盐缓冲液中加入 HRP 标记的异硫氰酸荧光素抗体, 使其与检测探针上的异硫氧酸苂光素结合, 在含有 TMB 的检测液中, 测量 HRP 催化产生的电信号. 该法 对来自 40 名患者的唾液样品进行盲法试验，结果表明 EFIRM 检测到 EGFR 中外显子 19 缺失, 曲线下面积为 0.94; L858R 突变, 曲线下面积为 0.96 . 曲线下面积越大, 表明 EFIRM 检测唾液中 EGFR 突变的准确性越高.

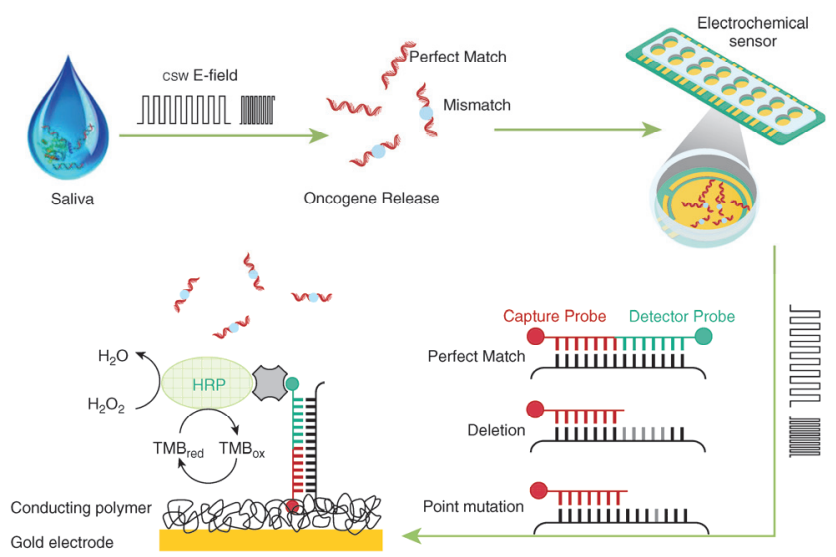

图 6 EFIRM 技术用于检测唾液中 EGFR 突变[78]

Figure 6 EFIRM technology for detecting EGFR mutations in saliva ${ }^{[78]}$

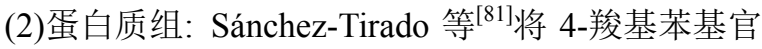
能化双壁碳纳米管(HOOC-Phe-DWCNTs)改性的双丝网 印刷碳电极(SPCE)作为固定抗体的支架，用于同时测定 IL- $\beta 1$ 和 TNF- $\alpha$. 如图 7 所示, 将捕获抗体 IL- $\beta 1$ 和 TNF- $\alpha$ 分别固定在电极后, 经靶蛋白、生物素化检测抗 体的夹心温育结合. 并进一步与聚 HRP-链霉亲和素缀 合，经过氧化氢一对苯二酚 $\left(\mathrm{H}_{2} \mathrm{O}_{2}-\mathrm{HQ}\right)$ 进行安培法测定. 该传感器对 IL- $\beta 1$ 、TNF- $\alpha$ 的线性范围分别为 $0.5 \sim 100$ 
表 5 双靶标电化学传感器

Table 5 Electrochemical sensor for dual targets

\begin{tabular}{|c|c|c|c|c|c|}
\hline Method & Electrode & Biomarkers & Detection range & LOD & Reference \\
\hline Chronoamperometry & Conducting polymer-array of AuE chip & EGFR gene mutations & - & - & {$[78]$} \\
\hline DPV & AuNP/PEDOT/CNT/SPCEs & hGH, PRL & $\begin{array}{l}0.05 \sim 1000 \mathrm{ng} \cdot \mathrm{mL}^{-1}(\mathrm{hGH}) \\
0.001 \sim 1000 \mathrm{ng} \cdot \mathrm{mL}^{-1}(\mathrm{PRL})\end{array}$ & $\begin{array}{l}4.4 \mathrm{pg} \cdot \mathrm{mL}^{-1}(\mathrm{hGH}) \\
0.22 \mathrm{pg} \cdot \mathrm{mL}^{-1}(\mathrm{PRL})\end{array}$ & [79] \\
\hline DPV & 4-ABA-rGO-SPdCEs & GHRL, PYY & $\begin{array}{l}10^{-3} \sim 100 \mathrm{ng} \cdot \mathrm{mL}^{-1}(\mathrm{GHRL}) \\
10^{-4} \sim 10 \mathrm{ng} \cdot \mathrm{mL}^{-1}(\mathrm{PYY})\end{array}$ & $\begin{array}{l}1.0 \mathrm{pg} \cdot \mathrm{mL}^{-1}(\mathrm{GHRL}) \\
0.02 \mathrm{pg} \cdot \mathrm{mL}^{-1}(\mathrm{PYY})\end{array}$ & {$[80]$} \\
\hline Amperometry & HOOC-Phe-DWCNTs/SPCEs & IL- $1 \beta$, TNF- $\alpha$ & $\begin{array}{l}0.5 \sim 100 \mu \mathrm{g} \cdot \mathrm{mL}^{-1}(\mathrm{IL}-1 \beta) \\
1 \sim 200 \mu \mathrm{g} \cdot \mathrm{mL}^{-1}(\mathrm{TNF}-\alpha)\end{array}$ & $\begin{array}{l}0.38 \mathrm{pg} \cdot \mathrm{mL}^{-1}(\mathrm{IL}-1 \beta), \\
0.85 \mathrm{pg} \cdot \mathrm{mL}^{-1}(\mathrm{TNF}-\alpha)\end{array}$ & [81] \\
\hline $\mathrm{CV}$ & CNT-SPCE & Hcy, GSH & $\begin{array}{l}5 \sim 20 \mu \mathrm{mol} \cdot \mathrm{L}^{-1}(\mathrm{Hcy}) \\
5 \sim 20 \mu \mathrm{mol} \cdot \mathrm{L}^{-1}(\mathrm{GSH})\end{array}$ & $\begin{array}{l}0.9 \mu \mathrm{mol} \cdot \mathrm{L}^{-1}(\mathrm{Hcy}) \\
2 \mu \mathrm{mol} \cdot \mathrm{L}^{-1}(\mathrm{GSH})\end{array}$ & {$[82]$} \\
\hline
\end{tabular}

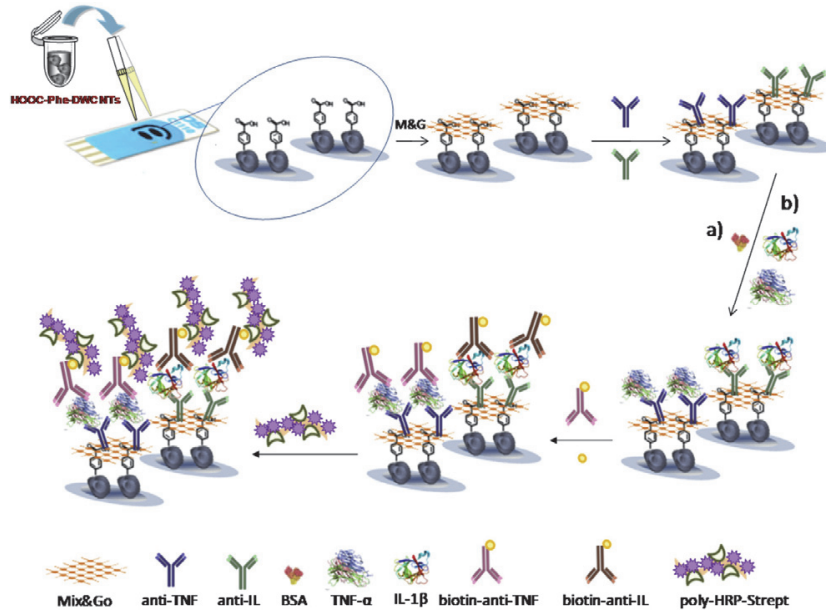

图 7 基于官能化双壁碳纳米管修饰电极的电化学传感器用于检测 IL-1 $\beta$ 和 TNF- $\alpha^{[81]}$

Figure 7 Electrochemical sensor based on functionalized double-walled carbon nanotube modified electrode for detection of IL-1 $\beta$ and TNF- $\alpha^{[81]}$

$\mu \mathrm{g} \bullet \mathrm{mL}^{-1} 、 1 \sim 200 \mu \mathrm{g} \bullet \mathrm{mL}^{-1}, \mathrm{LOD}$ 分别为 $0.38 \mathrm{pg} \bullet \mathrm{mL}^{-1}$ 、 $0.85 \mathrm{pg} \bullet \mathrm{mL}^{-1}$. 成功应用于以不同浓度水平掺入 IL- $\beta 1$ 和 TNF- $\alpha$ 的唾液样品, 回收率较好.

Martínez-García 等 ${ }^{[80]}$ 基于 4-氨基苯甲酸(4-ABA)/还 原氧化石墨烯( $\mathrm{rGO})$ 修饰丝网印刷双碳电极(SpdCEs)构 建同时测定生长激素释放肽(GHRL)、酪酪肽(PYY)的电 化学传感器. 如图 8 所示, SpdCEs 首先固载 GHRL、PYY 捕获抗体; 目标物、生物素标记目标物与捕获抗体竞争 性结合, 生物素标记的目标物与碱性磷酸酶链霉亲和素 (AP-Strept)进一步缀合, 以 1-NPP(1-菜基磷酸酯)作为碱 性磷酸酶催化反应底物, 经 DPV 分别测定 SpdCEs 双电 极端的峰电流. 唾液中 GHRL 和 PYY 的线性范围分别 为 $10^{-3} \sim 10 \mathrm{ng} \cdot \mathrm{mL}^{-1} 、 10^{-4} \sim 10 \mathrm{ng} \cdot \mathrm{mL}^{-1}$. 该传感器稳定 性和选择性较好, 并成功应用于加标人血清和唾液样品 的分析，回收率在 $96 \% \sim 103 \%$ 之间.

\subsection{2 组间双靶标}

口腔癌系唾液中多种复杂分子共同作用的结果, 将 基因水平的 DNA、调节水平的 RNA、功能水平的蛋白 质及一些微生物进行联合检测, 可从多角度来验证唾液 肿瘤生物标志物与口腔癌之间的相关性, 从而提高检测

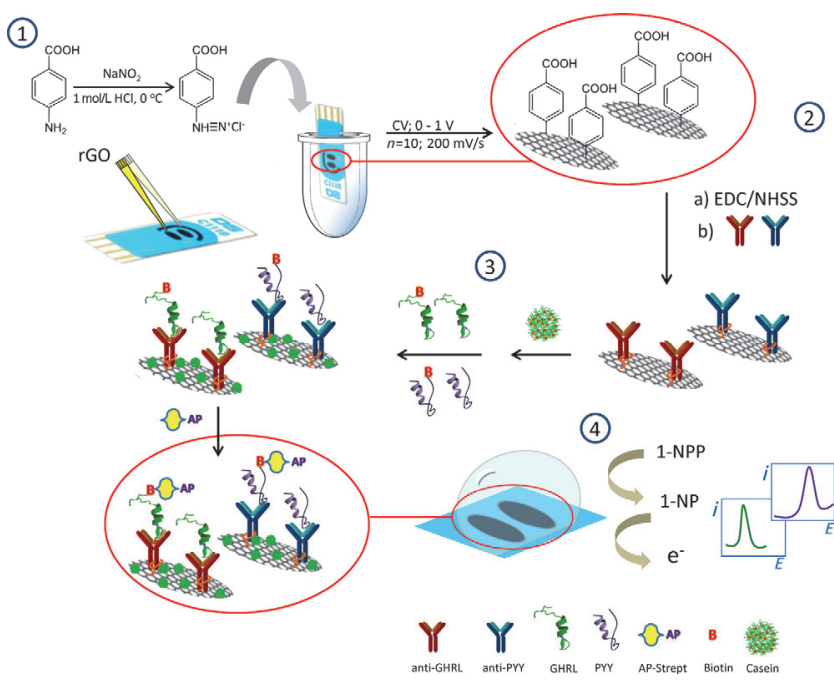

图 8 基于 $\mathrm{rGO}-\mathrm{SPdCEs}$ 上修饰 4-ABA 的电化学传感器用于检测 GHRL 和 PYY ${ }^{[80]}$

Figure 8 Electrochemical sensor based on modified 4-ABA on rGO-SPdCEs for detection of GHRL and PYY ${ }^{[80]}$

结果的准确性.

组间双靶标的检测大多发生在蛋白质组和转录组 之间. 最近 Torrente-Rodríguez 等 ${ }^{[83]}$ 使用双磁性印刷电 极(SPdCE, WE1 和 WE2 ) 同时测定人唾液样品中 IL-8 及 其信使 RNA(IL-8 mRNA)双靶标，方法如图 9 所示. 对 于 IL-8(WE1), 将捕获抗体 (C-Abs) 共价固定经 $\mathrm{EDC} / \mathrm{NHS}$ 活化的羧基修饰磁珠(HOOC-MB)上, 经 IL-8、生物素化的检测抗体(BD-Ab)构建三明治复合物, 并进一步以 HRP 标记生物素化的 BD-Ab. 对于 IL-8mRNA(WE2), 将生物素标记的发夹 DNA 序列 (B-HCpIL-8)与链霉亲和素修饰磁珠(Strep-MB)结合, 并 与生物素化的 IL-8mRNA 杂交, 进一步用 Strep-HRP 标 记生物素化的杂交体. 在各自对应的工作电极上, 使用 $\mathrm{HQ}$ 作为氧化还原介体用于监测双靶标的电流值. 该法 具有较高的灵敏度和选择性, 对 IL-8、IL-8 mRNA 的 $\mathrm{LOD}$ 分别为 $72.4 \mathrm{pg} \cdot \mathrm{mL}^{-1}$ 和 $0.21 \mathrm{nmol} \cdot \mathrm{L}^{-1}$. 该传感器成 功应用于加标原始唾液样品中的 IL-8、IL-8 mRNA 的检 测, 并确定唾液样品中 IL-8、IL-8 mRNA 的内源性含量, 其与 ELISA 试剂盒结果基本吻合. 


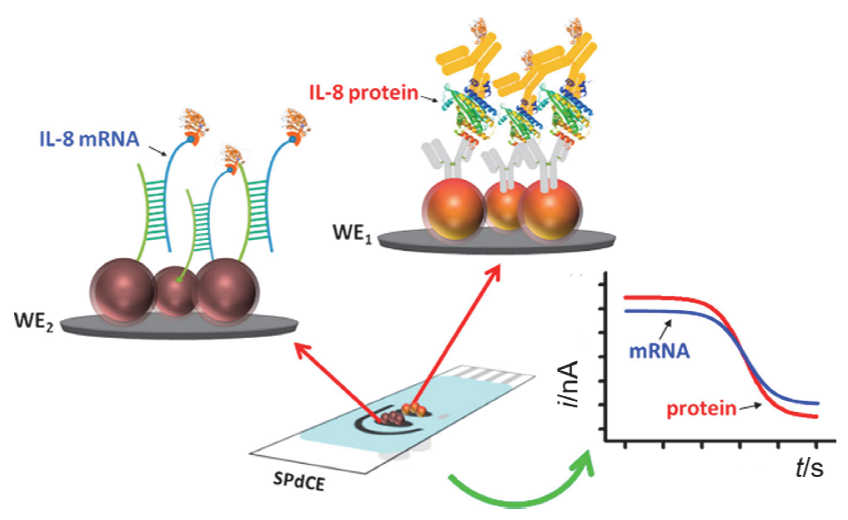

图 9 同时测定 IL-8 蛋白和 IL-8 mRNA 的双磁性传感器 ${ }^{[83]}$

Figure 9 Dual magnetic sensor for simultaneous determination of IL-8 protein and IL-8 $\mathrm{mRNA}^{[83]}$

\section{5 结论和展望}

唾液样本取材方便, 安全无创, 内含多种生物分子, 其与口腔癌的发生发展及治疗预后有着密切的诱因关 系. 纵观国内外的研究现状, 唾液肿瘤标志物的电化学 生物传感方法具有如下的发展趋势.

(1)组内靶标检测数量的增加. 目前, 各组唾液肿瘤 标志物的电化学传感仅见双靶标检测, 多靶标检测未见 相关文献报道. 未来可建立更多标志物的检测, 拓宽电 化学检测唾液肿瘤生物标志物的思路和手段.

(2)组间靶标检测种类的拓展. 由于转录组与蛋白 质组的表达密切相关, 加之抗原一抗体反应的高选择性 和敏感性, 目前文献报道仅见蛋白质组、转录组的组间 电化学检测. 开发研制用于联合检测多种组别的生物传 感分析平台是未来唾液肿瘤生物标志物电化学检测的 重点.

(3)传感检测实用性的提高. 目前电化学生物传感 器对唾液样本中标志物分子检测效果不理想. 将传感设 计与唾液样品前处理有效偶联, 集靶标提取、富集、检 测为一体, 有效提高传感器的实用性, 将是未来研究的 方向.

\section{作者简介}

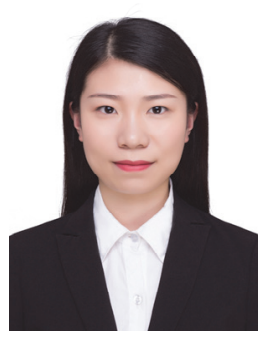

金金, 东南大学公共卫生学院 2017 级在读硕士, 研究方 向为肿瘤相关标志物纳米电化学分析检测研究.

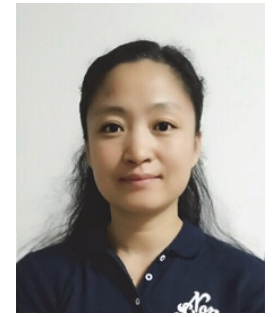

王晓英, 理学博士，东南大学公共卫生学院副教授，硕士 生导师。主要从事肿瘤相关标志物的生物传感与风险评估, 食品安全、环境污染相关的纳米电化学分析检测研究.

\section{References}

[1] Radhika, T.; Jeddy, N.; Nithya, S.; Muthumeenakshi, R. M. Jobcr. 2016, 6, S51.

[2] Kaczor-Urbanowicz, K. E.; Martin Carreras-Presas, C.; Kaczor, T.; Tu, M.; Wei, F.; Garcia-Godoy, F.; Wong, D. T. J. Cell. Mol. Med. 2017, 21(4), 640 .

[3] Sannam Khan, R.; Khurshid, Z.; Akhbar, S.; Faraz Moin, S. Proteomes. 2016, 4(4), 41.

[4] Saxena, S.; Sankhla, B.; Sundaragiri, K. S.; Bhargava, A. Adv. Biomed. Res. 2017, 6, 90

[5] Aps, J. K.; Martens, L. C. Forensic Sci. Int. 2005, 150(2-3), 119.

[6] Jensdottir, T.; Nauntofte, B.; Buchwald, C.; Bardow, A. Caries Res. 2005, 39(6), 468

[7] Kurgan, S.; Kantarci, A. Periodontol 2000 2018, 76(1), 51.

[8] Prasad, S.; Tyagi, A. K.; Aggarwal, B. B. Exp. Biol. Med. 2016, 241(8), 783.

[9] Yang, S. F.; Huang, H. D.; Fan, W. L.; Jong, Y. J.; Chen, M. K.; Huang, C. N.; Chuang, C. Y.; Kuo, Y. L.; Chung, W. H.; Su, S. C. Oral Oncol. 2018, 77, 1.

[10] Arantes, L.; De Carvalho, A. C.; Melendez, M. E.; Lopes Carvalho, A. Expert Rev. Mol. Diagn. 2018, $18(1), 85$.

[11] Zhang, Y.; Sun, J.; Lin, C.-C.; Abemayor, E.; Wang, M. B.; Wong, D. T. W. Periodontol 2000, 2016, 70(1), 38.

[12] Rosas, S. L. B.; Koch, W.; Carvalho, M. D. D.; Wu, L.; Califano, J.; Westra, W.; Jen, J.; Sidransky, D. Cancer Res. 2001, 61(3), 939.

[13] Zhang, L.; Rosin, M. P. J. Oral Pathol. Med. 2001, 30(9), 513.

[14] Rosin, M. P.; Cheng, X.; Poh, C.; Lam, W. L.; Huang, Y. Q.; Lovas, J.; Berean, K.; Epstein, J. B.; Priddy, R.; Le, N. D.; Zhang, L. W. Clin. Cancer Res. 2000, 6(2), 357.

[15] Wang, Y.; Springer, S.; Mulvey, C. L.; Silliman, N.; Schaefer, J.; Sausen, M.; James, N.; Rettig, E. M.; Guo, T.; Pickering, C. R.; Bishop, J. A.; Chung, C. H.; Califano, J. A.; Eisele, D. W.; Fakhry, C.; Gourin, C. G.; Ha, P. K.; Kang, H.; Kiess, A.; Koch, W. M.; Myers, J. N.; Quon, H.; Richmon, J. D.; Sidransky, D.; Tufano, R. P.; Westra, W. H.; Bettegowda, C.; Diaz, L. A., Jr.; Papadopoulos, N.; Kinzler, K. W.; Vogelstein, B.; Agrawal, N. Sci. Transl. Med. 2015, 7(293), 293 ra104.

[16] Vielba, R.; Bilbao, J.; Ispizua, A.; Zabalza, I.; Alfaro, J.; Rezola, R.; Moreno, E.; Elorriaga, J.; Alonso, I.; Baroja, A.; de la Hoz, C. Laryngoscope, 2003, 113(1), 167.

[17] Li, Y.; St John, M. A. R.; Zhou, X. F.; Kim, Y.; Sinha, U.; Jordan, R. C. K.; Eisele, D.; Abemayor, E.; Elashoff, D.; Park, N. H.; Wong, D. T. Clin. Cancer Res. 2004, 10(24), 8442.

[18] Park, N. J.; Zhou, H.; Elashoff, D.; Henson, B. S.; Kastratovic, D. A.; Abemayor, E.; Wong, D. T. Clin. Cancer Res. 2009, 15(17), 5473.

[19] St John, M. A. R.; Li, Y.; Zhou, X. F.; Denny, P.; Ho, C. M.; Montemagno, C.; Shi, W. Y.; Qi, F. X.; Wu, B.; Sinha, U.; Jordan, R.; Wolinsky, L.; Park, N. H.; Liu, H. H.; Abemayor, E.; Wong, D. T. W. Arch. Otolaryngol. 2004, 130(8), 929.

[20] Nagler, R.; Bahar, G.; Shpitzer, T.; Feinmesser, R. Clin. Cancer Res. 2006, 12(13), 3979.

[21] Wang, Y.; Gao, X.; Wei, F.; Zhang, X.; Yu, J.; Zhao, H.; Sun, Q.; Yan, F.; Yan, C.; Li, H.; Ren, X. Tumor Biol. 2015, 36(2), 1029.

[22] Shintani, S.; Hamakawa, H.; Ueyama, Y.; Hatori, M.; Toyoshima, T. Int. J. Oral Surg. 2010, 39(1), 68.

[23] Franzmann, E. J.; Reategui, E. P.; Pereira, L. H.; Pedroso, F.; Joseph, D.; Allen, G. O.; Hamilton, K.; Reis, I.; Duncan, R.; Goodwin, W. J.; Hu, J. J.; Lokeshwar, V. B. Head \& Neck, 2012, 34(5), 687. 
[24] Awasthi, N. Indian J. Pathol. Bacteriol. 2017, 60(4), 464.

[25] Zhang, X. Y.; Huang, Z. Q.; Hu, Y. J.; Liu, L. J. Oral Pathol. Med. 2016, 45(10), 740.

[26] Kang, M.-S.; Oh, J.-S.; Kim, H.-J.; Kim, H.-N.; Lee, I.-K.; Choi, H.-R.; Kim, O.-J.; Ko, Y.-J.; Lim, W.-B.; Park, H.-J.; Yu, M.-G.; Chung, K.-Y.; Kim, S.-M.; Lim, H.-S. J. Bacteriol. Virol. 2009, 39(4), 277.

[27] Sugimoto, M.; Wong, D. T.; Hirayama, A.; Soga, T.; Tomita, M. Metabolomics, 2010, 6(1), 78.

[28] Peres, J. C.; Rouquette, J. L.; Miocevic, O.; Warner, M. C.; Slowey, P. D.; Shirtcliff, E. A. Clin. Ther. 2015, 37(3), 515.

[29] Hasnis, E.; Reznick, A. Z.; Pollack, S.; Klein, Y.; Nagler, R. M. Int. J. Biochem. Cell Biol. 2004, 36(5), 826.

[30] Chiappin, S.; Antonelli, G.; Gatti, R.; De Palo, E. F. Clin. Chim. Acta.2007, 383(1-2), 30.

[31] Granger, D. A.; Kivlighan, K. T.; Fortunato, C.; Harmon, A. G.; Hibel, L. C.; Schwartz, E. B.; Whembolua, G.-L. Physiol. Behav. 2007, 92(4), 583.

[32] Gaykalova, D. A.; Vatapalli, R.; Wei, Y.; Tsai, H. L.; Wang, H.; Zhang, C.; Hennessey, P. T.; Guo, T.; Tan, M.; Li, R.; Ahn, J.; Khan, Z.; Westra, W. H.; Bishop, J. A.; Zaboli, D.; Koch, W. M.; Khan, T.; Ochs, M. F.; Califano, J. A. PLoS One, 2015, $10(11)$, e0142148.

[33] Schussel, J.; Zhou, X. C.; Zhang, Z.; Pattani, K.; Bermudez, F.; Jean-Charles, G.; McCaffrey, T.; Padhya, T.; Phelan, J.; Spivakovsky, S.; Brait, M.; Li, R.; Bowne, H. Y.; Goldberg, J. D.; Rolnitzky, L.; Robbins, M.; Kerr, A. R.; Sirois, D.; Califano, J. A. Clin. Cancer Res. 2013, 19(12), 3268.

[34] Hung, K. F.; Liu, C. J.; Chiu, P. C.; Lin, J. S.; Chang, K. W.; Shih, W. Y.; Kao, S. Y.; Tu, H. F. Oral Oncol. 2016, 53, 42.

[35] Xie, Z.; Chen, G.; Zhang, X.; Li, D.; Huang, J.; Yang, C.; Zhang, P.; Qin, Y.; Duan, Y.; Gong, B.; Li, Z. PLoS One 2013, 8(4), e57502.

[36] Katakura, A.; Kamiyama, I.; Takano, N.; Shibahara, T.; Muramatsu, T.; Ishihara, K.; Takagi, R.; Shouno, T. The Bulletin of Tokyo Dental College, 2007, 48(4), 199.

[37] Franzmann, E. J.; Reategui, E. P.; Pedroso, F.; Pernas, F. G.; Karakullukcu, B. M.; Carraway, K. L.; Hamilton, K.; Singal, R.; Goodwin, W. J. Cancer Epidemiol., Biomarkers Prev. 2007, 16(7), 1348.

[38] Hu, S.; Arellano, M.; Boontheung, P.; Wang, J.; Zhou, H.; Jiang, J.; Elashoff, D.; Wei, R.; Loo, J. A.; Wong, D. T. Clin. Cancer Res. 2008, 14(19), 6246.

[39] Dowling, P.; Wormald, R.; Meleady, P.; Henry, M.; Curran, A.; Clynes, M. J. Proteomics 2008, 71(2), 168.

[40] Jou, Y. J.; Lin, C. D.; Lai, C. H.; Tang, C. H.; Huang, S. H.; Tsai, M. H.; Chen, S. Y.; Kao, J. Y.; Lin, C. W. Clin. Chim. Acta 2011, 412, 1357.

[41] Jessie, K.; Jayapalan, J. J.; Ong, K. C.; Abdul Rahim, Z. H.; Zain, R. M.; Wong, K. T.; Hashim, O. H. Electrophoresis, 2013, 34(17), 2495.

[42] Hernández-Arteaga, A.; de Jesús Zermeño Nava, J.; Kolosovas-Machuca, E. S.; Velázquez-Salazar, J. J.; Vinogradova, E.; José-Yacamán, M.; Navarro-Contreras, H. R. Nano Res. 2017, 10(11), 3662.

[43] Schapher, M.; Wendler, O.; Groeschl, M.; Schaefer, R.; Iro, H.; Zenk, J. Clin. Chem. 2009, 55(5), 914.

[44] Shpitzer, T.; Hamzany, Y.; Bahar, G.; Feinmesser, R.; Savulescu, D.; Borovoi, I.; Gavish, M.; Nagler, R. M. Br. J. Cancer, 2009, 101(7), 1194.

[45] Elashoff, D.; Zhou, H.; Reiss, J.; Wang, J.; Xiao, H.; Henson, B.; Hu, S.; Arellano, M.; Sinha, U.; Le, A.; Messadi, D.; Wang, M.; Nabili, V.; Lingen, M.; Morris, D.; Randolph, T.; Feng, Z.; Akin, D.; Kastratovic, D. A.; Chia, D.; Abemayor, E.; Wong, D. T. W. Cancer Epidemiol., Biomarkers Prev. 2012, $21(4), 664$.

[46] Nagler, R.; Bahar, G.; Shpitzer, T.; Feinmesser, R. Clin. Cancer Res. 2006, 12(13), 3979.

[47] Ma, C. Y.; Zhang, C. P.; Zhong, L. P.; Pan, H. Y.; Chen, W. T.; Wang, L. Z.; Andrew, O. W.; Ji, T.; Han, W. Oncol. Rep. 2011, $26(4), 813$.

[48] Sawant, S. S.; Zingde, S. M.; Vaidya, M. M. Oral Oncol. 2008, 44(8), 722

[49] Yang, Y.; Rhodus, N. L.; Ondrey, F. G.; Wuertz, B. R.; Chen, X.; Zhu, Y.; Griffin, T. J. PLoS One 2014, 9(4), e95389.

[50] de Jong, E. P.; Xie, H.; Onsongo, G.; Stone, M. D.; Chen, X.-B.; Kooren, J. A.; Refsland, E. W.; Griffin, R. J.; Ondrey, F. G.; Wu, B.; Le, C. T.; Rhodus, N. L.; Carlis, J. V.; Griffin, T. J. PLoS One 2010 , 5(6), e11148.
[51] Mager, D. L.; Haffajee, A. D.; Devlin, P. M.; Norris, C. M.; Posner, M. R.; Goodson, J. M. J. Transl. Med. 2005, 3, 27.

[52] Wang, X.; Wang, Y.; Shan, Y.; Jiang, M.; Gong, M.; Jin, X.; Wang, X.; Cheng, J. Talanta 2018, 187, 179.

[53] Wang, X.; Wang, Y.; Shan, Y.; Jiang, M.; Jin, X.; Gong, M.; Xu, J. J. Electroanal. Chem. 2018, 823, 368.

[54] Tan, Y.; Wei, X.; Zhao, M.; Qiu, B.; Guo, L.; Lin, Z.; Yang, H. H. Anal. Chem. 2015, 87(18), 9204.

[55] Wei, F.; Wang, J.; Liao, W.; Zimmermann, B. G.; Wong, D. T.; Ho, C. M. Nucleic Acids Res. 2008, 36(11), e65.

[56] Wei, F.; Liao, W.; Xu, Z.; Yang, Y.; Wong, D. T.; Ho, C. M. Small 2009, 5(15), 1784.

[57] Wang, Z.; Zhang, J.; Guo, Y.; Wu, X.; Yang, W.; Xu, L.; Chen, J.; Fu, F. Biosens. Bioelectron. 2013, 45, 108.

[58] Li, H.; Zhang, W.; Zhou, H. Anal. Biochem. 2014, 449, 26.

[59] Choudhary, M.; Kumar, V.; Singh, A.; Singh, M. P.; Kaur, S.; Reddy, G. B.; Pasricha, R.; Singh, S. P.; Arora, K. Biosens. Bioelectron. 2013, 4,4

[60] Ojeda, I.; Moreno-Guzman, M.; Gonzalez-Cortes, A.; Yanez-Sedeno, P.; Pingarron, J. M. Anal. Bioanal. Chem. 2014, 406(25), 6363.

[61] Martínez-García, G.; Serafín, V.; Agüí, L.; Yáñez-Sedeño, P.; Pingarrón, J. M. Electroanalysis. 2015, 27(5), 1119.

[62] Kumar, S.; Sharma, J. G.; Maji, S.; Malhotra, B. D. Biosens. Bioelectron. 2016, 78, 497.

[63] Braiek, M.; Yang, Y.; Farre, C.; Chaix, C.; Bessueille, F.; Baraket, A.; Errachid, A.; Zhang, A.; Jaffrezic-Renault, N. Electroanalysis 2016, 28(8), 1810.

[64] Aydin, E. B.; Sezginturk, M. K. Anal. Biochem. 2018, 554, 44.

[65] Verma, S.; Singh, A.; Shukla, A.; Kaswan, J.; Arora, K.; Ramirez-Vick, J.; Singh, P.; Singh, S. P. ACS Appl. Mater. Interfaces 2017, 9(33), 27462.

[66] Aydın, E. B.; Aydın, M.; Sezgintürk, M. K. Sens. Actuators, B. 2018 , $270,18$.

[67] Choudhary, M.; Yadav, P.; Singh, A.; Kaur, S.; Ramirez-Vick, J.; Chandra, P.; Arora, K.; Singh, S. P. Electroanalysis 2016, 28(10), 2565.

[68] Kumar, S.; Sharma, J. G.; Maji, S.; Malhotra, B. D. RSC Adv. 2016, 6(80), 77037.

[69] Kumar, S.; Kumar, S.; Tiwari, S.; Srivastava, S.; Srivastava, M.; Yadav, B. K.; Kumar, S.; Tran, T. T.; Dewan, A. K.; Mulchandani, A.; Sharma, J. G.; Maji, S.; Malhotra, B. D. Adv. Sci. 2015, 2(8), 1500048 .

[70] Garcia, P. T.; Guimarães, L. N.; Dias, A. A.; Ulhoa, C. J.; Coltro, W K. T. Sens. Actuators, B 2018, 258, 342

[71] Aydin, E. B.; Aydin, M.; Sezginturk, M. K. Biosens. Bioelectron. 2017, 97, 169.

[72] Chen, Q.; Hu, W.; Shang, B.; Wei, J.; Chen, L.; Guo, X.; Ran, F.; Chen, W.; Ding, X.; Xu, Y.; Wu, Y. Microchim. Acta 2018, 185(3), 202.

[73] Pasha, S. K.; Kaushik, A.; Vasudev, A.; Snipes, S. A.; Bhansali, S. J. Electrochem. Soc. 2013, 161(2), B3077.

[74] Cullum, B. M.; McLamore, E. S.; Vabbina, P. K.; Kaushik, A.; Tracy, K.; Bhansali, S. Pala N. 2014, 9107, 91070U.

[75] Cullum, B. M.; McLamore, E. S.; Vabbina, P. K.; Kaushik, A.; Tracy, K.; Bhansali, S. Anal. Chem. 2017, 89(3), 2107.

[76] Wang, X.; Wang, Y.; Jiang, M.; Shan, Y.; Jin, X.; Gong, M.; Wang, X. Anal. Biochem. 2018, 548, 15.

[77] Ahmed, A.; Rushworth, J. V.; Wright, J. D.; Millner, P. A. Anal. Chem. 2013, 85(24), 12118.

[78] Wei, F.; Lin, C. C.; Joon, A.; Feng, Z.; Troche, G.; Lira, M. E.; Chia, D.; Mao, M.; Ho, C. L.; Su, W. C.; Wong, D. T. Am. J. Respir. Crit. Care Med. 2014, $190(10), 1117$.

[79] Serafin, V.; Martinez-Garcia, G.; Agui, L.; Yanez-Sedeno, P.; Pingarron, J. M. The Analyst. 2014, 139(18), 4556.

[80] Martínez-García, G.; Agüí, L.; Yáñez-Sedeño, P.; Pingarrón, J. M. Electrochim. Acta 2016, 202, 209.

[81] Sanchez-Tirado, E.; Salvo, C.; Gonzalez-Cortes, A.; Yanez-Sedeno, P.; Langa, F.; Pingarron, J. M. Anal. Chim. Acta 2017, 959, 66.

[82] Lee, P. T.; Compton, R. G. Sens. Actuators, B 2015, $209,983$.

[83] Torrente-Rodriguez, R. M.; Campuzano, S.; Ruiz-Valdepenas Montiel, V.; Gamella, M.; Pingarron, J. M. Biosens. Bioelectron. 2016 $77,543$.

(Cheng, B.; Fan, Y.) 